\title{
A frailty index derived from a standardized comprehensive geriatric assessment predicts mortality and aged residential care admission
}

Rosie Burn ${ }^{1}$, Ruth E. Hubbard ${ }^{2}$, Richard J. Scrase' ${ }^{1}$, Rebecca K. Abey-Nesbit ${ }^{3}$, Nancye M. Peel ${ }^{2}$, Philip J. Schluter ${ }^{4}$ and Hamish A. Jamieson ${ }^{1 *}$ (D)

\begin{abstract}
Background: Frailty in older adults is a condition characterised by a loss or reduction in physiological reserve resulting in increased clinical vulnerability. However, evidence suggests that frailty may be modifiable, and identifying frail older people could help better target specific health care interventions and services.

Methods: This was a regional longitudinal study to develop a frailty index for older adults living in Canterbury New Zealand. Participants included 5586 community dwelling older people that had an interRAI Minimum Data Set (MDS-HC) Home Care assessment completed between 2008 and 2012. The outcome measures were mortality and entry into aged residential care (ARC), after five years.

Results: Participants were aged between 65 and 101 (mean age was 82 years). The five-year mortality rate, including those who entered ARC, for this cohort was $67.1 \%(n=3747)$. The relationship between the frailty index and both mortality and entry into ARC was significant $(P<0.001)$. At five years, $25.1 \%(n=98)$ of people with a baseline frailty of $<0.1$ had died compared with $28.2 \%(n=22)$ of those with a frailty index of $\geq 0.5$ (FS 5). Furthermore, $43.7 \%(n=171)$ of people with a frailty index of $<0.1$ were still living at home compared to $2.6 \%(n=2)$ of those with a frailty index of $\geq 0.5$.

Conclusion: A frailty index was created that predicts mortality, and admission into ARC. This index could help healthcare professionals and clinicians identify older people at risk of health decline and mortality, so that appropriate services and interventions may be put in place.
\end{abstract}

Keywords: Aged care, Frailty index, Geriatric assessment, Community dwelling older people, Minimum data set

\section{Background}

Frailty is considered a condition in older people characterised by a loss of physiological reserve, which causes increased clinical vulnerability [1-3].

Frail older adults are vulnerable to changes in their health status to the extent that any assault on the body, such as a minor infection, or a fall can have disproportionately negative outcomes $[4,5]$. A measure of individual levels of frailty is needed to guide decision making, for example, when clinicians are considering treatment

\footnotetext{
* Correspondence: hamish.jamieson@otago.ac.nz

'University of Otago, Christchurch, New Zealand

Full list of author information is available at the end of the article
}

options in the aftermath of an acute episode or event, particularly as evidence suggests that frailty may be modifiable [6]. Identifying frail older adults would, therefore, help target specific health interventions and services needed to improve outcomes for this vulnerable cohort [1].

While there is a strong relationship between frailty and chronological age, frailty status is only one of many important factors that determine outcome; others include personal resources, social support and environmental factors, illness acuity and severity [7].

The measure of frailty has been considered using a phenotype model whereby the presence or absence of a

(c) The Author(s). 2018 Open Access This article is distributed under the terms of the Creative Commons Attribution 4.0 International License (http://creativecommons.org/licenses/by/4.0/), which permits unrestricted use, distribution, and reproduction in any medium, provided you give appropriate credit to the original author(s) and the source, provide a link to the Creative Commons license, and indicate if changes were made. The Creative Commons Public Domain Dedication waiver (http://creativecommons.org/publicdomain/zero/1.0/) applies to the data made available in this article, unless otherwise stated. 
pre defined set of five specific signs and symptoms are used to measure the degree of frailty of a specific individual [8]. Alternatively, frailty has been viewed from the perspective of an accumulation of deficits in the form of a frailty index [9]. A robust frailty index requires a significant number of individual items which are utilised to record deficit accumulation, and which are recorded as a score or index. This can also then be monitored in subsequent assessments to record the effectiveness or otherwise of specific interventions aimed at reducing an individual's level of frailty [10].

A frailty index was recently developed using a standardised assessment of patients in acute care in Australia: the interRAI acute care (AC) instrument [6]. Using the methodology of Searle et al., 2008, [11] specific variables, common to all interRAI instruments, were identified within the assessment as potential health deficits. The interRAI-AC assessment used in that study is part of a validated interRAI suite of assessment tools, which also includes the Minimum Dataset-Homecare (MDS-HC) assessment [12-14]. The different interRAI tools are specifically designed so that core questions are the same and as a consequence a person's health status can be tracked across different health settings using the appropriate interRAI assessment [15]. The MDS-HC assessment (recently updated and renamed as the interRAI Homecare assessment) is used in New Zealand to aid care of all older people living at home, who require publicly-funded community support or assessment for government-funded long-term residential care [16].

The MDS-HC has been demonstrated to be a valid and reliable electronic assessment tool. A detailed account of its successor, the interRAI-HC assessment instrument, has been described previously [16]. It includes 236 standardised questions analysing all aspects of an older person's life [16]. Anyone requiring public funding for health services in New Zealand is required to undergo a needs assessment. An individual can be referred by health professionals such as their general practitioner, hospital-based professionals or community health workers. Generally, individuals requiring home care services are referred by a general practitioner or other health professional. A trained assessor visits the individual in their own home to conduct the home care assessment, the assessor spends time asking questions from the assessment, and items within the assessment include standardised responses with definitions and observational time periods. Assessors also refer to external health information such as patient records to ensure a complete and accurate picture of the individual's health at time of assessment [15].

Using the recent Australian Frailty Index as a framework for our study, [6] we aimed to develop and validate a frailty score for the Canterbury, New Zealand community dwelling older people using local MDS-HC data.

\section{Methods}

A regional longitudinal study was used to develop a frailty scale for older adults living in Canterbury, New Zealand. Outcome measures were mortality and entry into aged residential care (ARC) over a 5-year period. All data were anonymised. Ethics permission was granted by the New Zealand Ministry of Health and Disability Ethics Committee (14/STH/140).

Participants included 5586 community dwelling older people who had a MDS-HC assessment completed between 2008 and 2012, while living in the Canterbury province of New Zealand.

The MDS-HC is a standardised, geriatric, home care assessment consisting of over 200 questions, which are used to guide individual care planning. Assessments are conducted by trained assessors and each assessment is recorded electronically. Assessors visit the patient in person and ask questions, perform physical assessments and use up to date medical records.

Answers to 42 questions from the MDS-HC assessment were selected as variables in this study. The criteria for variable deficits from a recent Australian study were used in the selection of these variables [6]. Variables were recoded into deficits as described in the supplementary section. Most of the questions used in the frailty index were recorded on a binary scale of 0 or 1 where 1 represents the presence of the deficit and 0 represents the absence. For example, when a person's memory was assessed, it was recorded as $0=$ Memory is fine or $1=$ Memory problem. These variables were directly translated into

Table 1 Frailty index ranges

\begin{tabular}{lllllll}
\hline Failty index ranges & $0-0.99$ & $0.1-0.19$ & $0.2-0.29$ & $0.3-0.39$ & $0.4-0.49$ & 4 \\
Frailty scale & 0 & 1 & 2 & 3 & 5.5 & 5 \\
Total^ $^{(\%)}$ & $391(7.0)$ & $1960(35.1)$ & $1993(35.7)$ & $877(15.7)$ & $287(5.1)$ & $78(1.4)$ \\
Female $^{*}(\%)$ & $198(50.6)$ & $1191(60.8)$ & $1265(63.5)$ & $551(62.8)$ & $178(62)$ & $45(58)$ \\
Male $^{+}(\%)$ & $193(49.4)$ & $769(39.2)$ & $728(36.5)$ & $326(37.2)$ & $109(38)$ & $33(42)$ \\
Mean age & 80.5 & 81.2 & 82.2 & 83.6 & 83.0 \\
\hline
\end{tabular}

${ }^{\text {TTotal people }}=5586 ;{ }^{*}$ total female $=3428(61 \%) ;{ }^{+}$total male $=2158(38.1 \%)$ 
Table 2 Patient characteristics

Variable (Deficit score)
Cognitive skills for daily decision making

$$
0
$$$$
0.5
$$$$
1
$$

Short Term memory

$$
0
$$$$
1
$$

Procedural memory

$$
0
$$$$
1
$$

Worsening of decision making

$$
0
$$$$
1
$$

Agitated or disoriented

$$
\begin{aligned}
& 0 \\
& 1
\end{aligned}
$$

Sudden or new onset/change in mental function

$$
0
$$$$
1
$$

Making self understood

$$
0
$$$$
0.5
$$$$
1
$$

Ability to understand others

$$
0
$$$$
0.5
$$$$
1
$$

Hearing

$$
0
$$$$
0.5
$$$$
1
$$

Vision

0

0.5

1

Withdrawal from activities of interest

$$
0
$$$$
0.5
$$$$
1
$$

Repetitive anxious complaints, concerns

$$
0
$$$$
0.5
$$

Frequency (\%)

$3631(65.0)$

1536 (27.5)

$419(7.5)$

$3241(58.0)$

$2345(42.0)$

4541 (81.3)

$1045(18.7)$

$4530(81.1)$

$1056(18.9)$

5262 (94.2)

324 (5.8)

$5448(97.5)$

138 (2.5)

$4482(80.2)$

$987(17.7)$

$117(2.1)$

$4272(76.5)$

1169 (20.9)

145 (2.6)

$2812(50.3)$

\begin{tabular}{|c|c|}
\hline Variable (Deficit score) & Frequency (\%) \\
\hline 1 & $419(7.5)$ \\
\hline \multicolumn{2}{|l|}{ Sad, depressed } \\
\hline 0 & $4351(77.9)$ \\
\hline 0.5 & $691(12.4)$ \\
\hline 1 & $544(9.7)$ \\
\hline \multicolumn{2}{|l|}{ Behaviour Symptoms } \\
\hline 0 & $5280(94.5)$ \\
\hline 1 & $203(3.6)$ \\
\hline 2 & $72(1.3)$ \\
\hline 3 & $31(0.6)$ \\
\hline \multicolumn{2}{|c|}{ Changes in behaviour symptoms } \\
\hline 0 & $5320(95.2)$ \\
\hline 1 & $266(4.8)$ \\
\hline \multicolumn{2}{|c|}{ Changes in social functioning } \\
\hline 0 & $3116(55.8)$ \\
\hline 0.5 & $1688(30.2)$ \\
\hline 1 & $782(14.0)$ \\
\hline \multicolumn{2}{|l|}{ Bathing } \\
\hline 0 & $2530(45.3)$ \\
\hline 0.5 & $1733(31.0)$ \\
\hline 1 & $1323(23.7)$ \\
\hline \multicolumn{2}{|l|}{ Personal hygiene } \\
\hline 0 & $4411(79.0)$ \\
\hline 0.5 & $340(6.1)$ \\
\hline 1 & $835(14.9)$ \\
\hline \multicolumn{2}{|l|}{ Dressing upper body } \\
\hline 0 & $3922(70.2)$ \\
\hline 0.5 & 1095 (19.6) \\
\hline 1 & $569(10.2)$ \\
\hline \multicolumn{2}{|l|}{ Dressing lower body } \\
\hline 0 & $3621(64.8)$ \\
\hline 0.5 & $1209(21.6)$ \\
\hline 1 & $756(13.5)$ \\
\hline \multicolumn{2}{|l|}{ Indoor mobility } \\
\hline 0 & $3362(60.2)$ \\
\hline 0.5 & 2077 (37.2) \\
\hline 1 & $147(2.6)$ \\
\hline \multicolumn{2}{|l|}{ Outdoor mobility } \\
\hline 0 & $2565(45.9)$ \\
\hline 0.5 & $2282(40.9)$ \\
\hline 1 & $739(13.2)$ \\
\hline
\end{tabular}

2676 (47.9)

$98(1.8)$

$4047(72.4)$

953 (17.1)

$586(10.5)$

4849 (86.8)

$275(4.9)$

$462(8.3)$

4783 (85.6)

$384(6.9)$
Table 2 Patient characteristics (Continued) 
Table 2 Patient characteristics (Continued)

\begin{tabular}{|c|}
\hline Variable (Deficit sco \\
\hline 0 \\
\hline 0.5 \\
\hline 1 \\
\hline Toilet use \\
\hline 0 \\
\hline 0.5 \\
\hline 1 \\
\hline Bed mobility \\
\hline 0 \\
\hline 0.5 \\
\hline 1 \\
\hline Eating \\
\hline 0 \\
\hline 0.5 \\
\hline 1 \\
\hline Mobility in home \\
\hline 0 \\
\hline 0.5 \\
\hline 1 \\
\hline Mode of locomotior \\
\hline 0 \\
\hline 0.5 \\
\hline 1 \\
\hline Activities of daily liv \\
\hline 0 \\
\hline 1 \\
\hline Bladder continence \\
\hline 0 \\
\hline 0.5 \\
\hline 1 \\
\hline Bowel continence \\
\hline 0 \\
\hline 0.5 \\
\hline 1 \\
\hline Disease diagnoses \\
\hline 0 \\
\hline 1 \\
\hline 2 \\
\hline 3 \\
\hline 4 \\
\hline 5 \\
\hline 6 \\
\hline
\end{tabular}

Frequency (\%)
$4848(86.8)$
$519(9.3)$
$219(3.9)$

4749 (85.0)

173 (3.1)

664 (11.9)

5078 (90.9)

96 (1.7)

$412(7.4)$

5186 (92.8)

188 (3.4)

$212(3.8)$

4835 (86.6)

$339(6.1)$

$412(7.4)$

3777 (67.6)

727 (13.0)

$1082(19.4)$

2716 (48.6)

2870 (51.4)

3581 (64.1)

1165 (20.9)

$840(15.0)$

4817 (86.2)

555 (9.9)

214 (3.8)

$140(2.5)$

603 (10.8)

1081 (19.4)

1335 (23.9)

1070 (19.2)

$666(11.9)$

$365(6.5)$
Table 2 Patient characteristics (Continued)

\begin{tabular}{|c|c|}
\hline Variable (Deficit score) & Frequency (\%) \\
\hline 7 & 201 (3.6) \\
\hline 8 & $77(1.4)$ \\
\hline 9 & $32(0.6)$ \\
\hline 10 & $9(0.2)$ \\
\hline 11 & $7(0.1)$ \\
\hline \multicolumn{2}{|l|}{ Falls } \\
\hline 0 & $3297(59.0)$ \\
\hline 1 & $2058(36.8)$ \\
\hline 2 & $127(2.3)$ \\
\hline 3 & $104(1.9)$ \\
\hline \multicolumn{2}{|l|}{ Unsteady gait } \\
\hline 0 & 2049 (36.7) \\
\hline 1 & 3537 (63.3) \\
\hline \multicolumn{2}{|l|}{ Pain frequency } \\
\hline 0 & $1855(33.2)$ \\
\hline 0.5 & $717(12.8)$ \\
\hline 1 & $3014(54.0)$ \\
\hline \multicolumn{2}{|l|}{ Pain intensity } \\
\hline 0 & 1875 (33.6) \\
\hline 0.5 & $970(17.4)$ \\
\hline 1 & $2741(49.1)$ \\
\hline \multicolumn{2}{|l|}{ Character of pain } \\
\hline 0 & 1910 (34.2) \\
\hline 0.5 & $1896(33.9)$ \\
\hline 1 & 1780 (31.9) \\
\hline \multicolumn{2}{|l|}{ Morbid obesity } \\
\hline 0 & $5477(98.0)$ \\
\hline 1 & $109(2.0)$ \\
\hline \multicolumn{2}{|l|}{ Weight loss } \\
\hline 0 & $4683(83.8)$ \\
\hline 1 & $903(16.2)$ \\
\hline \multicolumn{2}{|l|}{ Swallowing } \\
\hline 0 & $5057(90.5)$ \\
\hline 0.5 & $514(9.2)$ \\
\hline 1 & $15(0.3)$ \\
\hline \multicolumn{2}{|l|}{ Pressure ulcer } \\
\hline 0 & $5387(96.4)$ \\
\hline 1 & 199 (3.6) \\
\hline \multicolumn{2}{|l|}{ Medications } \\
\hline 0 & $115(2.1)$ \\
\hline 1 & $1057(18.9)$ \\
\hline 2 & $2269(40.6)$ \\
\hline
\end{tabular}


Table 2 Patient characteristics (Continued)

\begin{tabular}{|c|c|}
\hline Variable (Deficit score) & Frequency \\
\hline 3 & $2145(38.4)$ \\
\hline \multicolumn{2}{|l|}{ Congestive Heart Failure } \\
\hline Not present & $4352(77.9)$ \\
\hline Present & $157(2.8)$ \\
\hline Present and treated & $1077(19.3)$ \\
\hline \multicolumn{2}{|c|}{ Coronary Artery Disease } \\
\hline Not present & $4227(75.7)$ \\
\hline Present & $223(4.0)$ \\
\hline Present and treated & $1136(20.3)$ \\
\hline \multicolumn{2}{|l|}{ Hypertension } \\
\hline Not present & $2775(49.7)$ \\
\hline Present & $351(6.3)$ \\
\hline Present and treated & $2460(44.0)$ \\
\hline \multicolumn{2}{|l|}{ Alzheimer's } \\
\hline Not present & $5375(96.2)$ \\
\hline Present & $57(1.0)$ \\
\hline Present and treated & $154(2.8)$ \\
\hline \multicolumn{2}{|c|}{ Dementia other than Alzheimer's } \\
\hline Not present & $5279(94.5)$ \\
\hline Present & $98(1.8)$ \\
\hline Present and treated & $209(3.7)$ \\
\hline \multicolumn{2}{|l|}{ Parkinsonism } \\
\hline Not present & $5328(95.4)$ \\
\hline Present & $33(0.6)$ \\
\hline Present and treated & $225(4.0)$ \\
\hline \multicolumn{2}{|l|}{ Arthritis } \\
\hline Not present & $3243(58.1)$ \\
\hline Present & $533(9.5)$ \\
\hline Present and treated & $1810(32.4)$ \\
\hline \multicolumn{2}{|l|}{ Osteoporosis } \\
\hline Not present & $4427(79.3)$ \\
\hline Present & $212(3.8)$ \\
\hline Present and treated & $947(17.0)$ \\
\hline \multicolumn{2}{|c|}{ Any psychiatric diagnosis } \\
\hline Not present & $4726(84.6)$ \\
\hline Present & $160(2.9)$ \\
\hline Present and treated & $700(12.5)$ \\
\hline \multicolumn{2}{|l|}{ Urinary Tract Infection } \\
\hline Not present & $5232(93.7)$ \\
\hline Present & $47(0.8)$ \\
\hline Present and treated & $307(5.5)$ \\
\hline Cancer & \\
\hline
\end{tabular}

Table 2 Patient characteristics (Continued)

\begin{tabular}{ll}
\hline Variable (Deficit score) & Frequency (\%) \\
\hline Not present & $4792(85.8)$ \\
Present & $116(2.1)$ \\
Present and treated & $678(12.1)$ \\
Diabetes & \\
Not present & $4643(83.1)$ \\
Present & $166(3.0)$ \\
Present and treated & $777(13.9)$ \\
Emphysema/COPD/Asthma & \\
Not present & $4431(79.3)$ \\
Present & $173(3.1)$ \\
Present and treated & $982(17.6)$ \\
\hline
\end{tabular}

deficits. For ordinal and continuous variables, the answers were generally graded into deficits between 0 and 1 , such as $0,0.5$, and 1 . Thirty-eight of the 42 original variables were directly recoded into 38 potential deficits, while four variables had weightings on their deficit score. Three potential deficits were assigned to "behavioural symptoms", "number of falls", and "number of medications", and 15 for "count of disease diagnosis". This created a maximum score of 62. See Additional file 1 for the list of diseases in the interRAI-MDS.

The frailty index was calculated by summing the number of deficits recorded for a patient and dividing by the total number of possible deficits. This created a frailty index with a potential range from 0 to 1 . In instances where data was missing, the frailty index was calculated with an appropriately reduced denominator, so for example if a person was missing data for one item the maximum score was reduced to 61 . Anyone with a denominator of less than 30 was omitted from the study. In this study, there were no missing variables, the entire cohort had a denominator of 62 .

For comparative purposes, the $0-1$ frailty index was recoded into a 6-point frailty scale, where each person was allocated a score between 0 and 5 with 0 being the least frail and 5 being the frailest (Table 1). The scores on the scale correspond to the index as follows: Frailty Scale FS 0 having $0 \leq \mathrm{FI}<0.1$, FS 1 having $0.1 \leq \mathrm{FI}<0.2$, FS 2 having $0.2 \leq \mathrm{FI}<0.3$, FS 3 having $0.3 \leq \mathrm{FI}<0.4$, FS 4 having $0.4 \leq \mathrm{FI}<0.5$, and FS 5 having $\mathrm{FI} \geq 0.5$.

Dates of death were provided by the New Zealand Births, Deaths and Marriages dataset and matched to encrypted unique national identifier numbers. The NHI or National Health Index number is the unique person identifier used throughout the New Zealand public health system. Residential care entry date was obtained from the Contracted Care Payment System of the New Zealand Ministry of Health. 
Normality of the results was tested using the Kolmogorov-Smirnov test. Kaplan-Meier curves were used to discern the relationships between the frailty scale and mortality and admission to residential care, after five years.

\section{Results}

The total sample consisted of 5586 Canterbury District Health Board (CDHB), New Zealand, MDS-HC assessments. Participants were aged between 65 and 101 years, with a mean age of 82 years (SD 8.6 years). Most were females $(3428 ; 61.3 \%)$ and European New Zealanders (4837, 86.6\%). Individuals appeared to be cognitively healthy overall, however, over half of participants (2870, 51.4\%) experienced a decline in ADLs and the majority have 2 or more disease diagnoses. The mean age increased with frailty (Table 1). Table 2 features a count of deficits used in creating the frailty index.

The frailty index had a mean of 0.27 (SD 0.12) and a range from 0.01 to 0.7 . The index was not normally distributed (Fig. 1).

The five-year mortality rate was $67.1 \%(n=3747)$. The relationship between the frailty score and mortality was significant $\left(X^{2}(5)=332.2 ; P<0.001\right)$. At five years, $25.1 \%$ ( $n=98)$ of people with a baseline frailty of $<0.1$ had died compared with $28.2 \%(n=22)$ of those with a frailty index of $\geq 0.5$ (FS 5), (Fig. 2a).

After five years 2670 (47.8\%) of people had entered ARC. The relationship between the frailty index and admissions to residential care was also significant $\left(\chi^{2}(5)=\right.$ 252.67; $P<0.001)$. At five years, $43.7 \%(n=171)$ of people with a baseline frailty index of $<0.1$ (FS 0) were still living at home, compared to $2.6 \%(\mathrm{n}=2)$ of those with a frailty index of $\geq 0.5$ (FS 5),(Fig. 2b).

\section{Discussion}

In this study we demonstrated that a frailty index developed from the interRAI MDS-HC assessment was significantly associated with five-year admission to residential care and mortality.

An Australian study used interRAI (AC) data from 1418 older adults presenting to acute hospitals in Queensland and Victoria formed the basis of our study [6].

This Australian study found a slightly higher mean frailty index (0.32; SD 0.14) than that of our work (0.27; SD 0.12) [6]. This difference could reflect the different settings of both studies: acute hospital care versus community dwelling. However, both studies had a similar dose response relationship for predicting mortality.

A recent large UK study, which calculated 36 deficits from pre-existing primary care health records, developed an electronic frailty index with four validated levels of frailty in over 900,000 older people [1]. Outcome measures over one-, three-, and five-year periods highlighted good predictive validity for emergency hospital admission, mortality, and nursing home admission. Survival rates were lower in our study than the UK study which could reflect our investigation's focus on more frail and vulnerable members of a community dwelling population, rather than the general older population. The UK

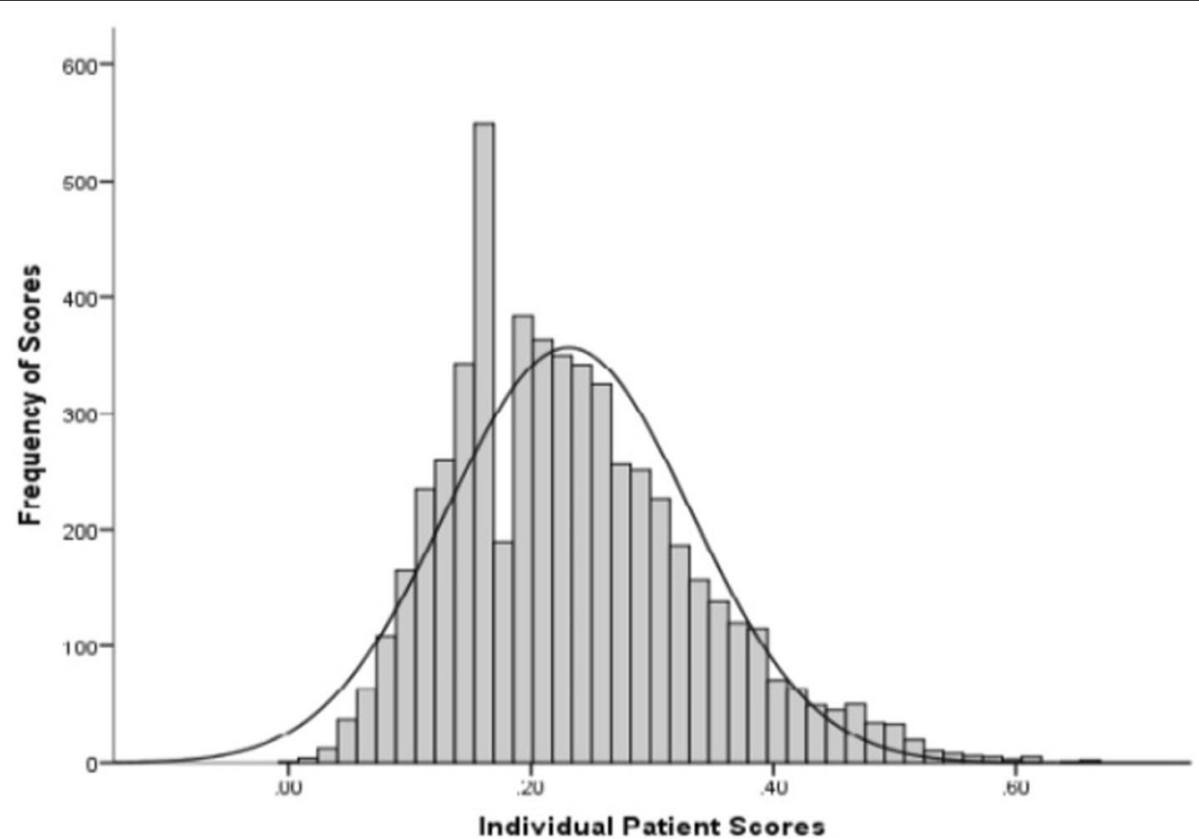

Fig. 1 Distribution of Frailty Index 
a Survival Rate
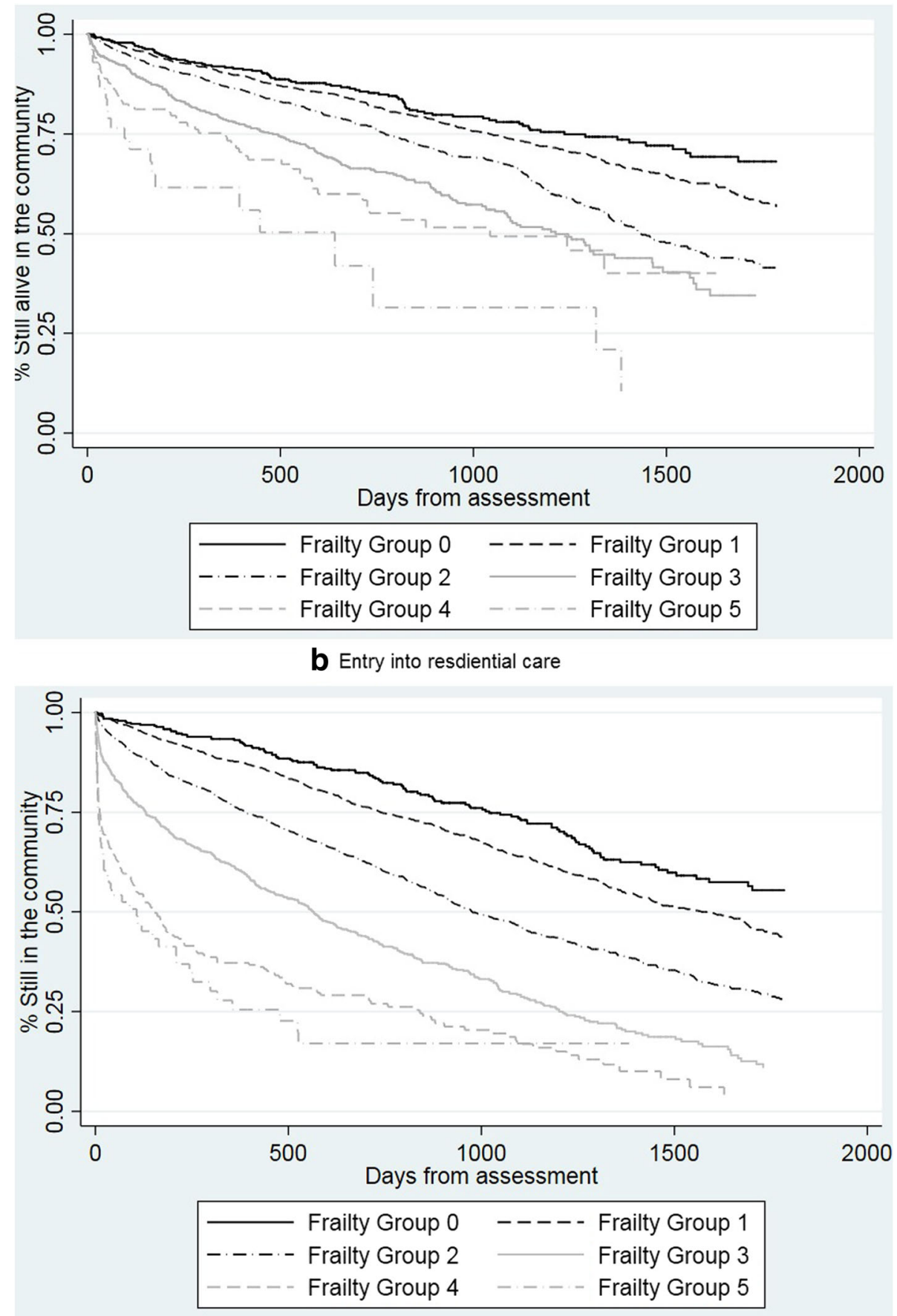

Fig. 2 Survival Curves of a Mortality and Grouped Frailty, b Entry to ARC and Grouped Frailty

study demonstrated that risk of hospitalisation and length of hospital stay increased incrementally with the degree of frailty.

Another study of community dwelling older people contextualised frailty scores against clinical descriptors, [17] and found a mean FI of 0.27 for patients who were mildly frail, with limited dependence on others for instrumental activities of daily living. This is consistent with the findings of our study.

The MDS-HC assessment prepopulates the Change in Health, End Stage Disease (CHESS) score from 12 specific questions to create a 6 point score [18]. 
Although it is a valuable tool, the CHESS score is a measure of a person's health instability rather than frailty and it focuses on recent changes in an individual's health and level of function and does not include longer term indicators of frailty such as comorbidities and baseline activities of daily living (ADL) function. The larger number of potential deficits in our score allows for the identification of modifiable components which could be targeted to improve outcomes for individuals, such as exercise, nutrition programmes, and medication reviews to help reduce the effects of polypharmacy [7].

There are a number of other validated frailty scales, $[1,9,19]$ but a significant advantage of our study and its utilisation of MDS-HC data, is that it allows for a comprehensive multi-dimensional perspective that aims to capture the complex nature of frailty without the need for further time consuming assessment. Furthermore, the fact that the interRAI suite of assessment tools are used over a number of different health settings means that individual levels of frailty using a standardised frailty index can be recorded both over time and across a variety of settings.

We acknowledge however, that this study utilised data from one region in New Zealand and that it may not be generalisable beyond this region. Additional work using this data set at a national level may be useful in identifying any ethnic differences in regard to frailty. Further work using New Zealand's national MDS-HC dataset will assist in understanding this index's generalisability including predicting other outcomes such as number and length of hospital admissions. We did not differentiate between frail individuals living at home or receiving daily care from those who live alone, and acknowledge that outcomes may have been poorer for the latter individuals.

\section{Conclusion}

A frailty index was developed from Canterbury's MDS-HC assessment data. From the index an easy to use scale was developed which could aid clinicians identify older people at risk of health decline and mortality. Frailty is not an inevitable part of ageing and nor should it be a barrier to interventions. It has the potential to be addressed and the individual's outlook improved if it is identified early enough and the appropriate healthcare investigations, or services are initiated.

\section{Additional file}

Additional file 1: RAN. This is a file containing information on how the frailty index was calculated. (DOCX 29 kb)

\section{Acknowledgements}

We thank Joanne Deely for assistance with writing and editing the manuscript and response to reviewers.

\section{Funding}

We are grateful for the support of the Canterbury Healthcare of the Elderly Education Trust and the Canterbury Osteoporosis Society and the Health Research Council of New Zealand. The funders made no contribution to the design, execution and analysis of the study.

\section{Availability of data and materials}

The data that support the findings of this study are available from Canterbury District Health Board but restrictions apply to the availability of these data, which were used under license for the current study, and so are not publicly available. Data are however available from the authors upon reasonable request and with permission of Canterbury District Health Board.

\section{Authors' contributions}

RB Conducted initial analysis and wrote methods and results draft. REH Provided clinical and analytical advice on the creation of the frailty index, made edits to paper. RJS Did literature review and wrote introduction and discussion, plus provided edits. RKAN Conducted extra analyses, made edits to paper. NMP Provided clinical and analytical advice on the creation of the frailty index, made edits to paper. PJS Provided statistical supervision and guidance, and made edits to paper. HAJ Designed the study and obtained funding. Assisted with clinical and analytical decision making, and helped edit the manuscript. All authors read and approved the final manuscript.

\section{Ethics approval and consent to participate}

Ethics permission was granted by the New Zealand Ministry of Health and Disability Ethics Committee (14/STH/140). All data has been anonymised and consent has been given by participants for any interRAl data to be used for research purposes. Only those who consented to their information being used for planning and research purposes were included in the study.

Consent for publication

Not Applicable.

\section{Competing interests}

The authors declare that they have no competing interests.

\section{Publisher's Note}

Springer Nature remains neutral with regard to jurisdictional claims in published maps and institutional affiliations.

\section{Author details}

${ }^{1}$ University of Otago, Christchurch, New Zealand. ${ }^{2}$ Centre for Research in Geriatric Medicine, The University of Queensland, Brisbane, Australia. ${ }^{3}$ Canterbury District health Board, Christchurch, New Zealand. ${ }^{4}$ University of Canterbury - Te Whare Wānanga o Waitaha, Christchurch, New Zealand.

Received: 18 January 2018 Accepted: 13 December 2018

Published online: 27 December 2018

\section{References}

1. Clegg A, Bates C, Young J, Ryan R, Nichols L, Teale EA, et al. Development and validation of an electronic frailty index using routine primary care electronic health record data. Age Ageing. 2016;45(3):353-60.

2. Morley J, Vellas B, Van Kan G, Anker S, Bauer J, Bernabei R, et al. Frailty consensus: a call to action. JAMDA. 2013;14:392-7.

3. Dent E, Chapman I, Howell S, Piantadosi C, Visvanathan R. Frailty and functional decline indices predict poor outcomes in hospitalised older people. Age Ageing. 2014;43(4):477-84.

4. Clegg A, Young J, lliffe S, Olde Rikkert M, Rockwood K. Frailty in elderly people. Lancet. 2013;381:752-62.

5. Fried L, Ferrucci L, Darer J, Williamson J, Anderson G. Untangling the concepts of disability, frailty, and comorbidity: implications for improved targeting and care. J Gerontol. 2004;59(3):255-63.

6. Hubbard R, N P. M S. derivation of a frailty index from the interRAl acute care instrument. BMC Geriatr. 2015;15(27).

7. Khatry K, Peel NM, Gray LC, Hubbard RE. The utility of the frailty index in clinical decision making. J Frailty Aging. 2018;7:138-41. https://doi.org/10. 14283/jfa.2018.7. 
8. Fried L, Tangen C, Walston J, Newman A, Hirsch C, Gottdiener J, et al. Frailty in Older Adults: Evidence for a Phenotype. J Gerontol A Biol Sci Med Sci. 2001;56A(3):M146-M56.

9. Rockwood K, Mitnitski A. Frailty defined by deficit accumulation and geriatric medicine defined by frailty. Clin Geriatr Med. 2011;27(1):17-26.

10. Cesari M, Gambassi G, Abellan van Kan G, Vellas B. The frailty phenotype and the frailty index: different instruments for different purposes. Age Ageing. 2014;43(1):10-2.

11. Searle SD, Mitnitski A, Gahbauer EA, Gill TM, Rockwood K. A standard procedure for creating a frailty index. BMC Geriatr. 2008;8:24. https://doi.org/ 10.1186/1471-2318-8-24.

12. interRAl.HC. interRAI Home Care 2016 [9th May 2016]. Available from: http:// interrai.org/home-care.html. Accessed 13 Mar 2017.

13. Hirdes JP, Ljunggren G, Morris JN, Frijters DH, Finne Soveri H, Gray L, et al. Reliability of the interRAl suite of assessment instruments: a 12-country study of an integrated health information system. BMC Health Serv Res. 2008;8:277.

14. Wellens N, Deschodt M, Flamaing J, Moons P, Boonen S, Boman X, et al. First-generation versus third-generation comprehensive geriatric assessment instruments in the acute hospital setting: a comparison of the minimum geriatric screening tools (MGST) and the interRAl acute care (interRAI AC). J Nutr Health Aging. 2011;15(8):638-44.

15. Hirdes JP, Ljunggren G, Morris JN, Frijters DH, Soveri HF, Gray L, et al. Reliability of the interRAl suite of assessment instruments: a 12-country study of an integrated health information system. BMC Health Serv Res. 2008;8(1):277.

16. Schluter PJ, Ahuriri-Driscoll A, Anderson TJ, Beere P, Brown J, DalrympleAlford J, et al. Comprehensive clinical assessment of home-based older persons within New Zealand: an epidemiological profile of a national crosssection. Aust N Z J Public Health. 2016.

17. Rockwood K, Song X, MacKnight C, Bergman H, Hogan DB, McDowell I, Mitnitski A. a global clinical measure of fitness and frailty in elderly people. CMAJ 2005;173: 489-495; DOI: https://doi.org/https://doi.org/10.1503/cmaj. 050051

18. Hirdes JP, Frijters DH, Teare GF. The MDS-CHESS scale: a new measure to predict mortality in institutionalized older people. J Am Geriatr Soc. 2003; 51(1):96-100.

19. Rolfson D, Majumdar S, Tsuyuki R, Tahir A, Rockwood K. Validity and reliability of the Edmonton frail scale. Age Ageing. 2006;35(5):526-9.

Ready to submit your research? Choose BMC and benefit from:

- fast, convenient online submission

- thorough peer review by experienced researchers in your field

- rapid publication on acceptance

- support for research data, including large and complex data types

- gold Open Access which fosters wider collaboration and increased citations

- maximum visibility for your research: over $100 \mathrm{M}$ website views per year

At $\mathrm{BMC}$, research is always in progress.

Learn more biomedcentral.com/submissions 